\title{
Effect of hydraulic retention time on biohydrogen production and anaerobic microbial community
}

\author{
Zhen-Peng Zhang ${ }^{\text {a,b }}$, Kuan-Yeow Show ${ }^{\text {a,* }}$, Joo-Hwa Tay ${ }^{\text {a,b }}$, \\ David Tee Liang ${ }^{b}$, Duu-Jong Lee ${ }^{c}$, Wen-Ju Jiang ${ }^{d}$ \\ ${ }^{a}$ School of Civil and Environmental Engineering, Nanyang Technological University, N1\#1a-27, Nanyang Avenue, 639798 Singapore, Singapore \\ ${ }^{\mathrm{b}}$ Institute of Environmental Science and Engineering, Nanyang Technological University, 637723 Singapore, Singapore \\ ${ }^{\mathrm{c}}$ Department of Chemical Engineering, National Taiwan University, Taipei 10617, PR China \\ ${ }^{\mathrm{d}}$ Department of Environmental Science and Engineering, Sichuan University, Chengdu 610065, PR China \\ Received 20 February 2006; received in revised form 15 May 2006; accepted 16 May 2006
}

This article is dedicated to Wolf-Dieter Deckwer on the occasion of his 65th birthday.

\begin{abstract}
The effects of hydraulic retention time (HRT) on biohydrogen production and its mixed anaerobic microbial community grown with glucose were investigated in a continuous stirred tank reactor culture. Starting from a HRT of $50 \mathrm{~h}$ the culture was acclimated by stepwise HRT reduction until a steady-state was reached at a HRT of $8 \mathrm{~h}$ after 19 days. After that the culture was run with HRTs of $6 \mathrm{~h}, 8 \mathrm{~h}, 10 \mathrm{~h}$ and $12 \mathrm{~h}$, each lasting 9-15 days. Hydrogen, $\mathrm{CO}_{2}$ and dissolved products were daily measured. The species composition of the culture was ascertained using $16 \mathrm{~S}$ rDNA genes separated by denaturing gradient gel electrophoresis (DGGE). While a hydrogen yield of $1.6 \mathrm{~mol} / \mathrm{mol}$ glucose was found during the first steadystate at $8 \mathrm{~h} \mathrm{HRT} \mathrm{it} \mathrm{stabilized} \mathrm{at} 1.9$ in the following steady-states. The predominant dissolved products were butyrate and acetate in a ratio of about 2.1:1 and amounted to $82-94 \%$ of the total products. In the first $8 \mathrm{~h} \mathrm{HRT} \mathrm{period} \mathrm{also} \mathrm{propionate} \mathrm{was} \mathrm{found} \mathrm{in} \mathrm{an} \mathrm{amount} \mathrm{of} 9 \%$. It is concluded that the increase of the hydrogen yield after transition from $8 \mathrm{~h}$ to $6 \mathrm{~h}$ HRT is caused by a washout of the propionate producing population during the $6 \mathrm{~h}$ HRT period. In fact the fading of two 16S rDNA gene fragments was noticed in the DGGE profiles at the same time.
\end{abstract}

(C) 2006 Elsevier Ltd. All rights reserved.

Keywords: Anaerobic biohydrogen production; Hydraulic retention time; Mixed culture; Microbial community; Continuous stirred tank reactor; Denaturing gradient gel electrophoresis

\section{Introduction}

Energy is vital to global prosperity, yet dependence on fossil fuels as our primary energy source has been reported to be a major cause to global climate change, environmental degradation and health problems [1]. To exploit alternative energy sources has became a pressing agenda due to recent global energy concern as a result of skyrocketing demand but relatively limited resources of fossil fuels. Hydrogen has been recognized as a perfect, clean fuel because of its inherent oxidation chemistry with water as the only reaction product, without any greenhouse gases generated. Nearly $90 \%$ of hydrogen production at present, however, is generated in centralized thermochemical processes

\footnotetext{
* Corresponding author. Tel.: +65 67905282; fax: +65 67910676.

E-mail address: ckyshow@ntu.edu.sg (K.-Y. Show).
}

from nonrenewable sources such as natural gas thermal cracking and coal gasification [2]. Anaerobic fermentation route is a promising biological process for hydrogen production owing to the fact that hydrogen can be produced continuously at high rate from renewable organic compounds [3].

Studies on hydrogen production by anaerobic fermentation have been carried out using pure cultures of bacteria such as Enterobacter [4], Rhodopseudomonas [5], Bacillus [6], Citrobacter [5], Escherichia [7] and Clostridium [8] or combined bacteria, i.e., Clostridium and Enterobacter [9] to degrade monosaccharides and disaccharides, cellulose and starch in the laboratory-scale studies. The highest hydrogen conversion efficiency reported so far is $2.6 \mathrm{~mol} \mathrm{H} / \mathrm{mol}$ glucose obtained by Taguchi et al. using Clostridium [10]. On the other hand, it may be difficult to use a pure culture for hydrogen production from organic wastes since pure culture is easily out-competed by various non-hydrogen producers. 
However, utilizing mixed cultures for hydrogen production did not attract much attention, until in recent years a comparable hydrogen yield $\left(\sim 2.45 \mathrm{~mol} \mathrm{H}_{2} / \mathrm{mol}\right.$ glucose $)$ by mixed cultures rich in Clostridia originated from anaerobic digesters, composts, soil and other natural sources has been achieved [11-13].

Continuous stirred tank reactor (CSTR) processes have been widely used for fundamental studies of continuous anaerobic hydrogen production due to its well-mixing characteristics to allow hydrogen-producing bacteria to overcome mass transfer resistance $[14,15]$. Nevertheless, many factors are contributing to the continuous production of hydrogen by the mixed cultures in a CSTR, including system $\mathrm{pH}$ [16], hydraulic retention time (HRT) [17], temperature [6], carbon source [18] and its strength [19], metabolic pathways involved [20] and microbial diversity [21]. HRT is one of the important control parameters affecting continuous production of hydrogen, since HRT control can avoid the hydrogen utilization by hydrogen-consumers, such as the methanogens [22]. However, the reported optimum HRTs for hydrogen production are rather inconsistent and varies from $8 \mathrm{~h}$ for sucrose [23] and $12 \mathrm{~h}$ for glucose [24] to $18-24 \mathrm{~h}$ for brewery wastewater $[15,17]$.

The objective of the present study was to investigate the continuous production of hydrogen and its associated microbial community of the mixed culture at varying HRTs in a CSTR.

\section{Materials and methods}

\subsection{Seed sludge}

Anaerobically digested sludge obtained from a wastewater treatment plant in Singapore was used as inoculum. The collected sludge was sieved using a $425 \mu \mathrm{m}$ mesh, and the filtrate was stored in a $4{ }^{\circ} \mathrm{C}$ fridge. The seed sludge was heat treated at $98{ }^{\circ} \mathrm{C}$ for $2 \mathrm{~h}$ and acid treatment at a pH of 2 for $24 \mathrm{~h}$ before inoculation. Initial concentration of volatile suspended solids (VSS) in the reactors was determined to be about $3500 \mathrm{mg} / \mathrm{L}$.

\subsection{Feed composition}

The synthetic wastewater mainly consisting of glucose $(10 \mathrm{~g} / \mathrm{L})$ was used as feed, which also contained the following nutrients (mg/L): $200 \mathrm{NH}_{4} \mathrm{Cl}, 200$ peptone, $200 \mathrm{KH}_{2} \mathrm{PO}_{4}, 30 \mathrm{FeCl}_{3} \cdot 6 \mathrm{H}_{2} \mathrm{O}, 20 \mathrm{MgCl}_{2} \cdot 6 \mathrm{H}_{2} \mathrm{O}, 10 \mathrm{MnCl}_{2} \cdot 4 \mathrm{H}_{2} \mathrm{O}, 5$ $\mathrm{CoCl}_{2} \cdot 6 \mathrm{H}_{2} \mathrm{O}, 6 \mathrm{CaCl}_{2} \cdot 2 \mathrm{H}_{2} \mathrm{O}, 5 \mathrm{Cu}\left(\mathrm{NO}_{3}\right)_{2} \cdot 3 \mathrm{H}_{2} \mathrm{O}, 5 \mathrm{ZnSO}_{4} \cdot 7 \mathrm{H}_{2} \mathrm{O}$ and 5 $\mathrm{NiSO}_{4} \cdot 6 \mathrm{H}_{2} \mathrm{O}$.

\subsection{Experimental setup and operation}

A glass-made CSTR (Biostat B, B. Braun Biotech, Germany) was used in the present study. It had a working volume of $6 \mathrm{~L}$ with an internal diameter of $160 \mathrm{~mm}$ and a height of $345 \mathrm{~mm}$. The CSTR was covered with aluminum foil to avoid sun light and stirred at a constant rate of $280 \mathrm{rpm}$. The $\mathrm{pH}$ of mixed liquid in the reactor was controlled at $5.5 \pm 0.05$ with $4 \mathrm{M} \mathrm{NaOH}$ and $4 \mathrm{M} \mathrm{HCl}$ by automatic titration. The reactor was operated at a constant temperature of $37^{\circ} \mathrm{C}$ through a water jacket. The feed stored in a $4{ }^{\circ} \mathrm{C}$ fridge was pumped into the reactor by a peristaltic pump (Masterflex L/S, Cole-Parmer, USA). A level sensor and effluent peristaltic pump were used to control the slurry volume at a constant value. A $1.16 \mathrm{~L}$ gas-liquid separating bottle was connected to the effluent to measure the biogas carried by the effluent, thus daily amount of biogas production was equal to the biogas in the effluent plus the biogas released directly from headspace, which was measured by a wet gas meter (Ritter TG 05 , Germany).

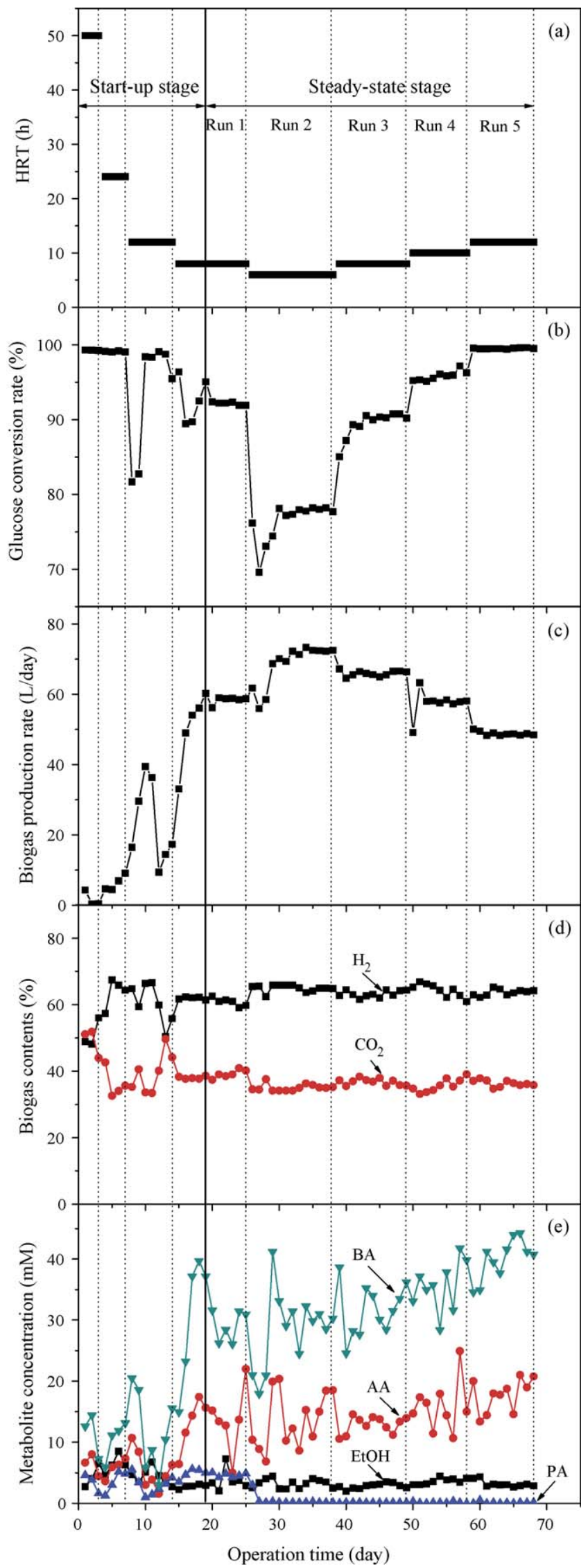

Fig. 1. Variations in: (a) HRT, (b) glucose conversion rate, (c) biogas production rate, (d) biogas contents and (e) soluble metabolites over time (AA, acetic acid; PA, propionic acid; BA, butyric acid; EtOH, ethanol). 
After inoculation, $10 \mathrm{~g}$ glucose was added to the reactor. The reactor was flushed with industrial argon gas for $10 \mathrm{~min}$ to create an anaerobic environment before the start-up of reactor. The reactor was initially operated for 1 day in batch mode without additional feed supply in order to avoid washout of inactivated biomass, and then converted to continuous operation. The HRTs were controlled in a shortening mode from $50 \mathrm{~h}$ to $8 \mathrm{~h}$ to start up the reactor. After reaching steadystate stage, the reactor was operated at HRTs of $8 \mathrm{~h}, 6 \mathrm{~h}, 8 \mathrm{~h}, 10 \mathrm{~h}$ and $12 \mathrm{~h}$. The reactor was operated for at least one week at each HRT for data collection. Steadystate conditions defined in the present study were considered to be reached when the variations of products along with biomass concentration were less than $10 \%$.

\subsection{Analytical methods}

Biogas contents: The biogas composition was analyzed by a Micro-Gas Chromatograph (Varian 4900, USA) equipped with a thermal conductivity detector. Hydrogen was analyzed using a Molsieve 5A Plot column with argon as carrier gas at $60^{\circ} \mathrm{C}$; methane and carbon dioxide were analyzed using a Propac Q column with helium as carrier gas at $60{ }^{\circ} \mathrm{C}$.

Aqueous samples: Aqueous samples were filtered through a $0.45 \mu \mathrm{m}$ membrane before analysis. Volatile fatty acids (VFAs) and alcohol were determined by a gas chromatograph (Agilent 6890 , USA) equipped with a mass selective detector $\left(220^{\circ} \mathrm{C}\right)$, injector $\left(200^{\circ} \mathrm{C}\right)$ and a $30 \mathrm{~m} \times 0.25 \mu \mathrm{m} \mathrm{HP}-$ FFAP fused-silica capillary column. The temperature of the oven was initially maintained at $60{ }^{\circ} \mathrm{C}$ for $4 \mathrm{~min}$, increased to $168^{\circ} \mathrm{C}$ at a ramp of $6{ }^{\circ} \mathrm{C} / \mathrm{min}$ and lastly heated to $200^{\circ} \mathrm{C}$ at $10^{\circ} \mathrm{C} / \mathrm{min}$ and maintained for $2 \mathrm{~min}$. Helium was used as the carrier gas. Glucose concentration was determined by the phenol-sulfuric acid method [25]. Measurements of VSS were performed according to the Standard Methods [26].

Microbial species composition: The microbial populations in hydrogenproducing community at each HRT condition were examined and compared by analyzing the denaturing gradient gel electrophoresis (DGGE) profiles of $16 \mathrm{~S}$ rDNA fragments. DNA in the sludge samples was extracted, and then the $16 \mathrm{~S}$ rDNA fragments were amplified by polymerase chain reaction (PCR), and separated by DGGE. For DNA extraction, a 100-200 mg sludge sample (wet weight) was mixed with $50 \mu \mathrm{L} 20 \%$ sodium dodecyl sulfate, $600 \mathrm{~mL}$ glass bead with a diameter of $0.1 \mathrm{~mm}$ and $500 \mu \mathrm{L}$ saturated phenol in a $2 \mathrm{~mL}$ tube and treated in a bead beater at 5000 oscillations/s for $3 \mathrm{~min}$. Subsequently, DNA extraction was carried out according to the protocols described previously [27,28]. The primers 357FGC (5'-CGC CCG CCG CGC GCG GCG GGC GGG GCG GGG GCA CGG GGG GCC TAC GGG AGG CAG CAG-3') and 517R (5'-ATT ACC GCG GCT GCT GG-3') were used for PCR amplification. A touchdown thermal profile technique [27] using $2 \mathrm{~min}$ for activation and $10 \mathrm{~min}$ for extension was performed. The DGGE was performed following the method described by Muyzer et al. [29]. Electrophoresis was conducted in a $1 \times \mathrm{TAE}$ buffer solution at $85 \mathrm{~V}$ and $60^{\circ} \mathrm{C}$ for $12 \mathrm{~h}$.

\section{Results and discussion}

\subsection{Hydrogen production}

The effect of HRT on hydrogen production was investigated in a completely mixed reactor at a consistent $\mathrm{pH}$ and temperature of $5.5^{\circ} \mathrm{C}$ and $37{ }^{\circ} \mathrm{C}$, respectively. The reactor mixing condition was ensured by keeping the variation of VSS concentrations to less than $5 \%$ at three different reactor heights, i.e., at $50 \mathrm{~mm}, 170 \mathrm{~mm}$ and $280 \mathrm{~mm}$ from the reactor bottom (data not shown).

The initial HRT was set at $50 \mathrm{~h}$ for reactor start-up. To accelerate the acclimation process of the mixed culture, HRT was shortened gradually once the glucose conversion rate reached $95 \%$ (Fig. 1a and b). A dynamic increase in biogas production was observed during the start-up stage (Fig. 1c). This is probably attributed to the fact that the microorganisms are adapting to the new environment resulted from the HRT shifting. Steady gas production was not observed until day 19 , at a HRT of $8 \mathrm{~h}$. After steady-state conditions were reached, the HRT was shortened to $6 \mathrm{~h}$, and then increased in an increment of 2-12 h. Five steady-state conditions, marked as Runs 1-5, were at least maintained for one week at each HRT before changing the HRT (Fig. 1 and Table 1). The biogas produced consisted of hydrogen and carbon dioxide and was free of methane throughout the study. The result thus lends support for the effectiveness of pretreatment protocol on inactivating methanogens. Hydrogen content increased from initially $49 \%$ to $67 \%$ at day 5 and thereafter leveled off (Fig. 1d). Hydrogen gas accounted for about $61 \%$ of total biogas evolved in Run 1 and increased to $64 \%$ in the following runs (Table 2). This value is much higher than that of other studies $(34-53 \%)[6,24,30]$ with the exception of Ueno et al. [31] who obtained the same level.

As summarized in Table 1, a hydrogen yield of $1.6 \mathrm{~mol} \mathrm{H}_{2} /$ mol glucose was obtained in Run 1, at which the reactor was operated at HRT $8 \mathrm{~h}$. Hydrogen yield increased by about $0.3 \mathrm{~mol} \mathrm{H}_{2} / \mathrm{mol}$ glucose when the HRT was shortened to $6 \mathrm{~h}$ in Run 2. However, a relatively consistent hydrogen yield of approximately $1.9 \mathrm{~mol} \mathrm{H}_{2} / \mathrm{mol}$ glucose was obtained as the HRTs were increased to $8 \mathrm{~h}, 10 \mathrm{~h}$ and $12 \mathrm{~h}$ in Runs 3, 4 and 5, respectively. The hydrogen production rate reached the maximum of $7.8 \mathrm{~L} / \mathrm{L}$ day at a HRT of $6 \mathrm{~h}$, and it decreased, but not in a linear trend, with increasing HRT, whereby glucose conversion rate increased from $77.8 \%$ at $6 \mathrm{~h}$ HRT to $99.4 \%$ at $12 \mathrm{~h}$ HRT. It is interesting to note that an increase of $0.8 \mathrm{~L} /$ $\mathrm{L}$ day in hydrogen production rate was obtained in Run 3 as compared to Run 1 , both at $8 \mathrm{~h}$ HRT, as a consequence of the increased hydrogen yield.

The biomass concentration retained in the reactor was in a range of $843-1013 \mathrm{mg} / \mathrm{L}$, but not in correlation with the HRT (Table 1). As only $77.8 \%$ of glucose was utilized at a HRT of $6 \mathrm{~h}$

Table 1

Reactor performance at steady-state stage

\begin{tabular}{|c|c|c|c|c|c|c|}
\hline Run no. & $\begin{array}{l}\text { Operating time } \\
\text { (day) }\end{array}$ & HRT (h) & VSS (mg/L) & $\begin{array}{l}\text { Glucose conversion } \\
\text { rate }(\%)^{\mathrm{a}}\end{array}$ & $\begin{array}{l}\mathrm{H}_{2} \text { yield } \\
\text { (mol H} \mathrm{H}_{2} / \text { mol glucose) }\end{array}$ & $\begin{array}{l}\mathrm{H}_{2} \text { production } \\
\text { rate ( } \mathrm{L} / \mathrm{L} \text { day) }\end{array}$ \\
\hline 1 & $20-25$ & 8 & $910.83 \pm 39.06^{b}$ & $91.63 \pm 0.20$ & $1.62 \pm 0.03$ & $6.08 \pm 0.19$ \\
\hline 2 & $26-38$ & 6 & $847.50 \pm 26.86$ & $77.82 \pm 0.38$ & $1.88 \pm 0.03$ & $7.77 \pm 0.13$ \\
\hline 3 & $39-49$ & 8 & $897.64 \pm 25.17$ & $90.46 \pm 0.30$ & $1.93 \pm 0.02$ & $6.92 \pm 0.03$ \\
\hline 4 & $50-58$ & 10 & $843.33 \pm 65.60$ & $96.24 \pm 0.52$ & $1.95 \pm 0.03$ & $6.11 \pm 0.07$ \\
\hline 5 & $59-68$ & 12 & $1013.33 \pm 95.57$ & $99.44 \pm 0.07$ & $1.91 \pm 0.02$ & $4.95 \pm 0.03$ \\
\hline
\end{tabular}

\footnotetext{
${ }^{\text {a }}$ Ten grams per litre in the influent.
}

b Mean value \pm standard deviation. 
it is not meaningful to shorten HRT to less than $6 \mathrm{~h}$ to further enhance the hydrogen production rate.

\subsection{Soluble metabolites}

Fig. 1e reveals the production of main VFAs and alcohol associated with the HRT. Butyric, acetic and propionic acids and ethanol were the main metabolites at the start-up, but butyric and acetic acids increased significantly and became the dominant metabolites after reaching steady-state stage. Butyric and acetic acids accounted for approximately $82-94 \%$ (molar percentage) of total metabolites, while relatively consistent percentage of ethanol (4.6-7.3\%) was obtained at the steady-state stage, regardless of the variation of HRT. Notably, considerable production of propionic acid was observed during the culture acclimation and first $8 \mathrm{~h}$ HRT (Run 1) periods, but it decreased to $0-0.18 \mathrm{mmol} / \mathrm{L}$ immediately after the HRT was transited from $8 \mathrm{~h}$ to $6 \mathrm{~h}$ (Fig. 1e). It appears that these propionate producers are highly sensitive to a low HRT and $6 \mathrm{~h}$ whereby might be a critical HRT to remove propionate producers from the system, which is supported by the durable absence of propionic acid during the HRT of 8-12 h in Runs 3-5. Consequently, a higher hydrogen yield would be expected as aforementioned, because propionate production involves consumption of both organic substrate and hydrogen which is produced in other pathways according to the theoretical equation (Eq. (1)).

$\mathrm{C}_{6} \mathrm{H}_{12} \mathrm{O}_{6}+2 \mathrm{H}_{2} \rightarrow 2 \mathrm{CH}_{3} \mathrm{CH}_{2} \mathrm{COOH}+2 \mathrm{H}_{2} \mathrm{O}$

The HRT could be used as a tool to select microbial populations whose growth rates are able to catch up with the mechanical dilution created by continuous volumetric flow [32]. That shorter retention time led to reduction of propionate production in anaerobic hydrogen production by mixed cultures has been reported $[6,18,33]$. Cha and Noike [33] noticed that propionate production was present at HRTs of $24 \mathrm{~h}$ and $48 \mathrm{~h}$ but absent at a HRT of $12 \mathrm{~h}$ in a chemostat test using starch as the substrate. Hussy et al. [18] found that immediate reduction of propionate production was observed in a continuous hydrogen fermentation from wheat starch as HRT was shortened to $12 \mathrm{~h}$. The propionate level decreased significantly as the HRT was shortened to $6 \mathrm{~h}$ in the study by Lin and Chang [6]. These results seem to provide evidence that the amount of propionate producers in the mixed cultures is influenced by the HRT. However, it was also noted that the propionate concentration did not vary markedly in a HRT range of 4-24 h [15,23], and even decreased with increasing HRT [34]. The hydraulic dilution effects in those studies appear rather inconsistent along with the present study. This is presumably due to the influence of other parameters such as substrate, inoculum and pretreatment protocol used. Nevertheless, the retention time did show an effect of hydraulic selection on the mixed culture in the present study.

Moreover, the ratio of butyric acid and acetic acid (BA/AA ratio) has been considered as a crucial indicator for evaluating the efficiency of hydrogen-producing cultures [22,35]. The ratios of butyrate and acetate obtained at steady-state conditions are summarized in Table 2, showing BA/AA ratios of 2.1-2.4, which are very close to the values reported by other 
researchers $[22,36]$. This corresponds to a maximal theoretical hydrogen yield of $2.4 \mathrm{~mol} \mathrm{H}_{2} / \mathrm{mol}$ glucose according to the fact that $4 \mathrm{~mol}$ and $2 \mathrm{~mol}$ of hydrogen are generated from $1 \mathrm{~mol}$ of glucose, when acetate and butyrate are produced, respectively. Since part of the glucose is shunted to the formation of ethanol and some other acids, i.e., valeric and hexanoic acids, which do not contribute to hydrogen production, a hydrogen yield of $1.95 \mathrm{~mol} \mathrm{H}_{2} / \mathrm{mol}$ glucose obtained in the present study is reasonable and consistent with that (1.70-2.45 mol $\mathrm{H}_{2} / \mathrm{mol}$ glucose) obtained in other studies using mixed cultures as the hydrogen producers [11,16,23,24].

\subsection{Microbial diversity}

The diversity of microbial communities at different HRTs was analyzed and compared by PCR-DGGE techniques, with the DGGE profiles of 16S rDNA gene fragments, as shown in Fig. 3. Each band on the DGGE profile corresponded to a gene fragment of unique $16 \mathrm{~S}$ rDNA sequences and accordingly represented a specific species in the microbial community. The intensity of a band represents the relative abundance of the corresponding microbial species [16,37].

The DGGE profiles clearly show a shift of microbial population with HRTs (Fig. 2). An apparently intense band, representing the dominant species on each lane was observed at each HRT after the reactor was started up as compared to the

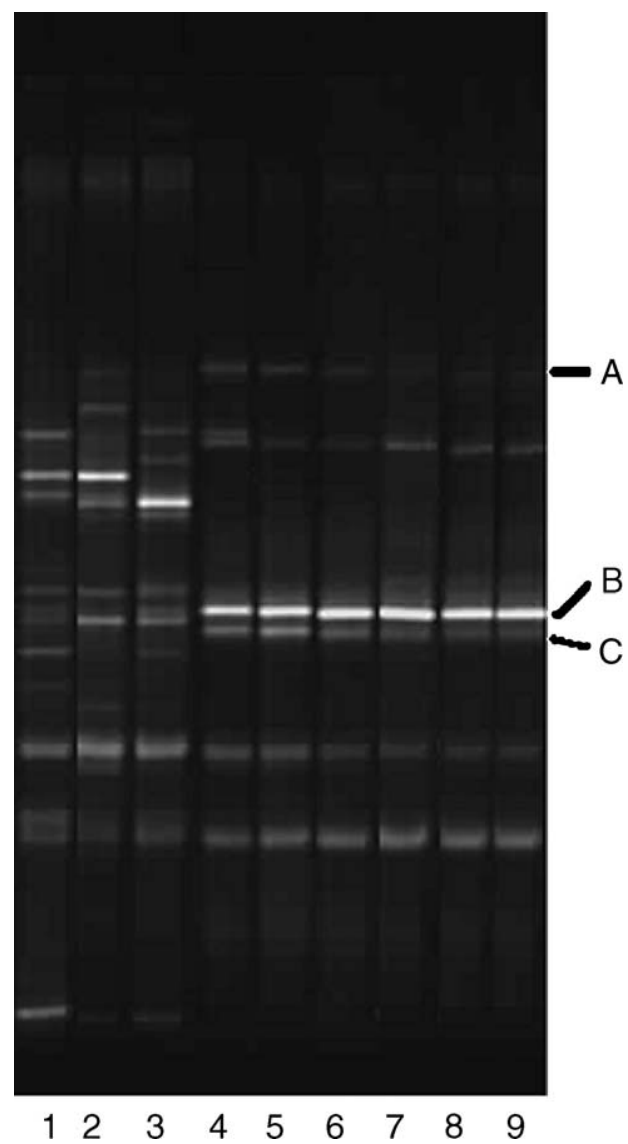

Fig. 2. Variation of DGGE profiles with HRTs (see Table 3 for the sampling times and HRTs associated with the lanes).
Table 3

Information of sludge samples for DGGE

\begin{tabular}{lll}
\hline Lane no. & HRT (h) & $\begin{array}{l}\text { Sampling } \\
\text { time (day) }\end{array}$ \\
\hline 1 & & 0 \\
2 & Seed $^{\mathrm{a}}$ & 2 \\
3 & 50 & 6 \\
4 & 24 & 10 \\
5 & 12 & 16 \\
6 & 8 & 24 \\
7 & 8 & 34 \\
8 & 6 & 47 \\
9 & 8 & 64 \\
\hline
\end{tabular}

a Seed sludge pretreated by heat and acid incubation.

seed sludge pretreated. The dominant species (the brightest band in Lanes 2-4), however, were still shifting until the HRT was shortened to $12 \mathrm{~h}$ during the start-up stage, which could have contributed to a varying increase of hydrogen production rate as observed. Thereafter, the dominant species (Band B) in the microbial community did not vary much. Moreover, the diversity of microbial communities decreased with the HRT shortening to $6 \mathrm{~h}$ as Bands $\mathrm{A}$ and $\mathrm{C}$ disappeared or faded, but after 15 days of acclimation it stabilized in Runs 2-5, regardless of the HRTs extended. This seems to be evidences with respect to microbiological aspect to support the washout effect of HRT on propionate producers. Comparing Lanes 5 and 6, whose sludge samples were taken at days 16 and 24, respectively, during the first $8 \mathrm{~h}$ HRT period no variation of microbial population can be seen, indicating that the microbial population did not change by the acclimation process itself but by the HRT shifts applied during this period.

In summary, shortening of the HRT to $6 \mathrm{~h}$ was able to reduce the diversity of microbial population associated with an elimination of propionate production without affecting the existence of dominant species, which was the presumable reason for the observed increase in hydrogen yield. On the other hand, steady microbial population and hydrogen yield observed as the HRT increased from $6 \mathrm{~h}$ to $12 \mathrm{~h}$ (Runs 2-5) indicate that hydrogen yield representing the capability of microorganisms to convert carbohydrate into hydrogen gas is independent of the HRT. As a result, the hydrogen yield could be considered as a function of the microbial populations in the culture, but the HRT affects the microbial community to a certain extent, and in turn shows an impact on hydrogen yield. This might explain the view of HRTdependent hydrogen yield obtained by some other researchers in the similar systems $[6,17,24]$. In Chen and Lin's study [23], for example, it is likely that the increased hydrogen yield from $0.57 \mathrm{~mol} \mathrm{H}_{2} / \mathrm{mol}$ glucose to $1.70 \mathrm{~mol} \mathrm{H}_{2} / \mathrm{mol}$ glucose with a shortened HRT from 2 days to 0.5 day resulted from the contributions of HRT-selected microbial population.

\section{Conclusions}

Based on the experimental results obtained, it can be concluded that the hydraulic retention time (HRT) appears to be 
a significant hydrodynamic selection on the mixed-microbial populations. A stable microbial population was established by washing out propionate producing bacteria as the HRT is shortened to $6 \mathrm{~h}$. An increase in the hydrogen yield from $1.6 \mathrm{~mol} \mathrm{H}_{2} / \mathrm{mol}$ glucose to $1.9 \mathrm{~mol} \mathrm{H}_{2} / \mathrm{mol}$ glucose was measured when the HRT was shortened from $8 \mathrm{~h}$ to $6 \mathrm{~h}$. Arising from the stabilized microbial population, the hydrogen composition and yield were maintained at about $64 \%$ and $1.9 \mathrm{~mol} \mathrm{H}_{2} / \mathrm{mol}$ glucose, respectively, in the subsequent operation at 8-12 h HRT.

\section{References}

[1] Levin DB, Pitt L, Love M. Biohydrogen production: prospects and limitations to practical application. Int J Hydrogen Energy 2004;29(2): 173-85.

[2] Das D, Veziroglu TN. Hydrogen production by biological processes: a survey of literature. Int J Hydrogen Energy 2001;26(1):13-28.

[3] Benemann J. Hydrogen biotechnology: progress and prospects. Nat Biotechnol 1996;14(9):1101-3.

[4] Kumar N, Das D. Enhancement of hydrogen production by Enterobacter cloacae IIT-BT 08. Process Biochem 2000;35(6):589-93.

[5] Oh Y-K, Seol E-H, Kim JR, Park S. Fermentative biohydrogen production by a new chemoheterotrophic bacterium Citrobacter sp. Y19. Int J Hydrogen Energy 2003;28(12):1353-9.

[6] Lin C-Y, Chang R-C. Fermentative hydrogen production at ambient temperature. Int J Hydrogen Energy 2004;29(7):715-20.

[7] Chittibabu G, Nath K, Das D. Feasibility studies on the fermentative hydrogen production by recombinant Escherichia coli BL-21. Process Biochem 2006;41(3):682-8.

[8] Wang CC, Chang CW, Chu CP, Lee DJ, Chang B-V, Liao CS. Producing hydrogen from wastewater sludge by Clostridium bifermentans. J Biotechnol 2003;102(1):83-92.

[9] Yokoi H, Maki R, Hirose J, Hayashi S. Microbial production of hydrogen from starch-manufacturing wastes. Biomass Bioenergy 2002;22(5):389-95.

[10] Taguchi F, Yamada K, Hasegawa K, Taki-Saito T, Hara K. Continuous hydrogen production by Clostridium sp. strain no. 2 from cellulose hydrolysate in an aqueous two-phase system. J Ferment Bioeng 1996; 82(1):80-3.

[11] Van Ginkel S, Sung SW, Lay JJ. Biohydrogen production as a function of $\mathrm{pH}$ and substrate concentration. Environ Sci Technol 2001;35(24):4726-30.

[12] Lin CY, Lee CY, Tseng IC, Shiao IZ. Biohydrogen production from sucrose using base-enriched anaerobic mixed microflora. Process Biochem 2006;41(4):915-9.

[13] Kim JO, Kim YH, Ryu JY, Song BK, Kim IH, Yeom SH. Immobilization methods for continuous hydrogen gas production biofilm formation versus granulation. Process Biochem 2005;40(3-4):1331-7.

[14] Majizat A, Mitsunori Y, Mitsunori W, Michimasa N, Jun'ichiro M. Hydrogen gas production from glucose and its microbial kinetics in anaerobic systems. Water Sci Technol 1997;36(6-7):279-86.

[15] Yu HQ, Hu ZH, Hong TQ. Hydrogen production from rice winery wastewater by using a continuously-stirred reactor. J Chem Eng Jpn 2003;36(10):1147-51.

[16] Fang HHP, Liu H. Effect of $\mathrm{pH}$ on hydrogen production from glucose by a mixed culture. Bioresour Technol 2002;82(1):87-93.
[17] Fan KS, Kan NR, Lay JJ. Effect of hydraulic retention time on anaerobic hydrogenesis in CSTR. Bioresour Technol 2006;97(1):84-9.

[18] Hussy I, Hawkes FR, Dinsdale R, Hawkes DL. Continuous fermentative hydrogen production from a wheat starch co-product by mixed microflora. Biotechnol Bioeng 2003;84(6):619-26.

[19] Kim SH, Han SK, Shin HS. Effect of substrate concentration on hydrogen production and 16S rDNA-based analysis of the microbial community in a continuous fermenter. Process Biochem 2006;41(1):199-207.

[20] Hartmanis M, Gatenbeck S. Intermediary metabolism in Clostridium acetobutylicum: levels of enzymes involved in the formation of acetate and butyrate. Appl Environ Microbiol 1984;47(6):1277-83.

[21] Kim JO, Kim YH, Yeom SH, Song BK, Kim IH. Enhancing continuous hydrogen gas production by the addition of nitrate into an anaerobic reactor. Process Biochem 2006;41(5):1208-12.

[22] Chen CC, Lin CY, Chang JS. Kinetics of hydrogen production with continuous anaerobic cultures utilizing sucrose as the limiting substrate. Appl Microbiol Biotechnol 2001;57(1-2):56-64.

[23] Chen CC, Lin CY. Using sucrose as a substrate in an anaerobic hydrogenproducing reactor. Adv Environ Res 2003;7(3):695-9.

[24] Lin CY, Chang RC. Hydrogen production during the anaerobic acidogenic conversion of glucose. J Chem Technol Biotechnol 1999;74(6):498-500.

[25] Dubois M, Gilles KA, Hamilton JK, Rebers PA, Smith F. Colorimetric method for determination of sugars and related substrates. Anal Chem 1956;28(3):350-6.

[26] APHA. Standard methods for the examination of water and wastewater, 19th ed., Washington, DC, USA: American Public Health Association; 1998.

[27] Watanabe K, Teramoto M, Futamata H, Harayama S. Molecular detection, isolation, and physiological characterization of functionally dominant phenol-degrading bacteria in activated sludge. Appl Environ Microbiol 1998;64(11):4396-402.

[28] Watanabe K, Yamamoto S, Hino S, Harayama S. Population dynamics of phenol-degrading bacteria in activated sludge determined by gyrB-targeted quantitative PCR. Appl Environ Microbiol 1998;64(4):1203-9.

[29] Muyzer G, de Waal E, Uitterlinden A. Profiling of complex microbial populations by denaturing gradient gel electrophoresis analysis of polymerase chain reaction-amplified genes coding for $16 \mathrm{~S}$ rRNA. Appl Environ Microbiol 1993;59(3):695-700.

[30] Chang J-S, Lee K-S, Lin P-J. Biohydrogen production with fixed-bed bioreactors. Int J Hydrogen Energy 2002;27(11-12):1167-74.

[31] Ueno Y, Otsuka S, Morimoto M. Hydrogen production from industrial wastewater by anaerobic microflora in chemostat culture. J Ferment Bioeng 1996;82(2):194-7.

[32] Tijhuis L, Vanloosdrecht MCM, Heijnen JJ. Formation and growth of heterotrophic aerobic biofilms on small suspended particles in airlift reactors. Biotechnol Bioeng 1994;44(5):595-608.

[33] Cha GC, Noike T. Effect of rapid temperature change and HRT on anaerobic acidogenesis. Water Sci Technol 1997;36(6-7):247-53.

[34] Dinopoulou G, Rudd T, Lester NJ. Anaerobic acidogenesis of a complex wastewater: I. The influence of operational parameters on reactor performance. Biotechnol Bioeng 1988;31(9):958-68.

[35] Nandi R, Sengupta S. Microbial production of hydrogen: an overview. Crit Rev Microbiol 1998;24(1):61-84.

[36] Kim IS, Hwang MH, Jang NJ, Hyun SH, Lee ST. Effect of low pH on the activity of hydrogen utilizing methanogen in bio-hydrogen process. Int $\mathrm{J}$ Hydrogen Energy 2004;29(11):1133-40.

[37] Zhang T, Fang HH. Phylogenetic diversity of a SRB-rich marine biofilm. Appl Microbiol Biotechnol 2001;57(3):437-40. 